Ind. Health, 1971, 9, 171.

\title{
PROBLEMS CONCERNING MOUNTING OF PICKUPS FOR VIBRATION LEVEL METER
}

\author{
Toshisuke MIWA and Yoshiharu YONEKAWA \\ National Institute of Industrial Health, Kizuki-Sumiyoshi, Kawasaki
}

(Received October 30, 1971)

\begin{abstract}
A vibration level meter with weighting network corresponding to human vibration sensation has recently been planned by the Acoustic Society of Japan to assess vibration pollution. However, weight, size and position of a sensing element of a vibration pickup of the vibration level meter have not been standardized. To determine optimum values for them, the contact resonance was examined on combinations of eleven mounting materials and seven vibration pickups on a vibration table of electrodynamic type in vertical and horizontal directions.

It was found that the vibration pickup which had weight of $300 \mathrm{~g}$ was desirable for vertical and horizontal vibrations under almost all mounting conditions except in the case of some special materials. The contact resonance frequency between the pickup and the mounting material was able to be elevated to a considerably high frequency for vertical vibration, but for horizontal vibration it was lowered until near half the value in vertical vibration. Therefore, vibration occurring in human environment is desirable to be measured by a VL range of the vibration level meter, in which the weighting circuit of the amplifier has the same frequency characteristics as those of human vibration sensation below $90 \mathrm{~Hz}$ and above it the cut-off frequency nature is $-18 \mathrm{~dB} /$ oct. Vibration pickup of the vibration level meter was able to be calibrated without bolting on the vibration table below $90 \mathrm{~dB}\left(0 \mathrm{~dB}=10^{-3} \mathrm{~cm} / \mathrm{sec}^{2}\right)$.
\end{abstract}

Residents who live near construction work sites, highways, railways and factories frequently complain of vibration pollution. In such cases, it is needed to measure a certain vibration value corresponding to grades of human vibration sensation, not a pure physical value such as displacement, velocity or acceleration. Specification of an apparatus for measurement of this vibration value called "Vibration Level Meter"1) has been proposed by Subcommittee for Vibration Measurement in the Acoustic Society of Japan (Chairman, Dr. J. Igarashi, Professor of the University of Tokyo), in which a network corresponding to the human vibration sensation proposed by International Organization for Standardization (ISO/TC 108/ WG 7$)^{2)}$ has been prepared for weighting input voltages of the vibration acceleration pickup defined as a VL range. In this specification, however, weighting circuit for the horizontal vibration was decided to be the same as the vertical vibration sensation for convenience. On the vibration pickup, size, weight and the setting position of a sensing element have not yet been standardized, because of 


\section{T. MIWA AND Y. YONEKAWA}

lack of the basic data for mounting conditions. The vibration level meters commercially available now in Japan have not been unified in these points. Therefore, result of vibration measurement may considerably be influenced by characteristics of the mounting conditions of vibration pickups.

Eleven kinds of the mounting samples encountered practically were vibrated on a vibration table of dynamic type in vertical and horizontal directions and seven kinds of the vibration pickups were placed on these samples to observe their frequency characteristics from 10 to $300 \mathrm{~Hz}$.

Mounting problems of the vibration pickups studied by us in the present paper are those in the surface vibration among several kinds of vibrations.

\section{EXPERIMENTAL Procedures}

Eleven kinds of mounting materials were examined as shown in Table 1. These samples are classified in three categories.

Table 1. Eleven kinds of mounting samples.

\begin{tabular}{|c|c|c|c|c|}
\hline & Samples & Weight (kg) & Size $(\mathrm{mm})$ & $\begin{array}{l}\text { Bolts number } \\
\text { for fixing on } \\
\text { vibration table }\end{array}$ \\
\hline 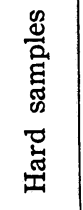 & $\begin{array}{l}\text { Aluminum disc } \\
\text { Concrets block } \\
\text { Light weight block } \\
\text { Fire brick (ISOLITE, N-5) } \\
\text { Vinyl-tile }\end{array}$ & $\begin{array}{l}4 \\
7.7 \\
7 \\
1 \\
0.48\end{array}$ & $\begin{array}{l}17 \times 340 \phi \\
350 \times 40 \times 250 \\
390 \times 150 \times 190 \\
230 \times 63 \times 113 \\
305 \times 305 \times 2\end{array}$ & $\begin{array}{c}6 \\
2 \\
2 \\
2 \\
\text { Adhesive }\end{array}$ \\
\hline 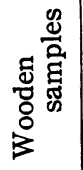 & $\begin{array}{l}\text { Plywood plate } \\
\text { Lauan plate } \\
\text { Wooden-fiber cemented-plate } \\
\text { Cypress rectangular lumber }\end{array}$ & $\begin{array}{l}1.4 \\
2.5 \\
1.8 \\
3\end{array}$ & $\begin{array}{l}25 \times 370 \phi \\
480 \times 265 \times 43 \\
25 \times 360 \phi \\
480 \times 116 \times 116\end{array}$ & $\begin{array}{l}6 \\
4 \\
6 \\
2\end{array}$ \\
\hline 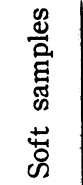 & $\begin{array}{l}\text { Soil in aluminum box } \\
\text { Aluminum box } \\
\text { Tatami (Japanese mat) }\end{array}$ & $\begin{array}{l}35 \text { (Total weight) } \\
21 \\
1.4\end{array}$ & $\begin{array}{l}\text { Inside sizes of } \\
450 \times 450 \times 200 \text { and } \\
\text { thickness of } 20 \\
300 \times 300 \times 65\end{array}$ & $\begin{array}{c}\text { One sheet of } \\
\text { paper without } \\
\text { bolts } \\
2\end{array}$ \\
\hline
\end{tabular}

i) Hard samples; Aluminum plate, concrete-block, light-weight block, fire blick and vinyl-tile.

ii) Wooden samples; Plywood plate, cypress rectangular lumber, lauan plate and wooden-fiber cemented plate.

iii) Soft samples; Soil and Japanese mat (Tatami).

These samples are frequently encountered for the vibration measurement either inside or outside of the house in Japan. The vibration on soil must frequently be measured for assessment of the vibration pollution, because local governments in Japan have stipulated regulations in which the vibration pollution shall be evaluated 


\section{MOUNTING OF VIBRATION PICKUPS}

by the value on the ground of the borderline between the house of distressed residents and the vibration sources. As general Japanese houses use Japanese mat on the floor, vibration measurement on it is required, especially for assessment of vibration pollution. These samples except the soil in the box were fixed on the vibration table by bolts of which numbers were shown in Table 1 . Soil in the garden of our institute was put in the aluminum box as also described in Table 1 and was trodden hard enough. To avoid the resonance caused from the vibration table and this aluminum box, a sheet of paper was placed between the table and the box.

Table 2. Seven kinds of vibration pickups for vibration level meter.

\begin{tabular}{c|l|c|c|c|c}
\hline $\begin{array}{c}\text { Vibration } \\
\text { pickup }\end{array}$ & \multicolumn{1}{|c|}{ Type } & $\begin{array}{c}\text { Length of } \\
\text { legs }(\mathrm{mm})\end{array}$ & $\begin{array}{c}\text { Weight } \\
(\mathrm{kg})\end{array}$ & $\begin{array}{c}\text { Size } \\
(\mathrm{mm})\end{array}$ & Amplifier \\
\hline A & Ceramic & without & 1.5 & $60 \times 60 \times 108$ & $-2 \mathrm{~dB} /$ oct, above $90 \mathrm{~Hz}$ \\
B & Electro-dynamic & 3 & 1.9 & $60 \times 60 \times 108$ & $-5 \mathrm{~dB} /$ oct, above $90 \mathrm{~Hz}$ \\
C & Ceramic & 25 & 2.5 & $93 \times 106 \times 73$ & $-9 \mathrm{~dB} /$ oct, above $90 \mathrm{~Hz}$ \\
D & Ceramic & 3 & 0.8 & $50 \times 50 \times 54$ & Flat, below $1 \mathrm{kHz}$ \\
I & Ceramic & 4 & 0.3 & Outside dia, $50 \phi$ & $\mathrm{d}^{\circ}$ \\
II & Ceramic & 4 & 0.6 & Outside dia, $65 \phi$ & $\mathrm{d}^{\circ}$ \\
III & Ceramic & 4 & 1.2 & Outside dia, $86 \phi$ & $\mathrm{d}^{\circ}$ \\
\hline
\end{tabular}

The inside diameter and the height of pickups I, II and III were the same as $35 \mathrm{~mm} \phi$ and $30 \mathrm{~mm}$ respectively, and the usual vibration accelerometer of ceramic type (weight of $36 \mathrm{gr}$. and size of $30 \mathrm{~mm} \times 15 \mathrm{~mm} \phi$ ) was commonly used as the sensing element, provided that a small aluminum block (weight of $18 \mathrm{gr}$.) was used for setting when this accelerometer was employed in the vertical direction.

Seven vibration pickups were examined as shown in Table 2. Among them four pickups, A, B, C and D were commercially available and the other three pickups, I, II and III were tentatively made. It must be noticed that amplifiers of the former three pickups (A, B and C) made by their makers were used, while an amplifier produced by us was employed for the other pickups. Their cut-off frequency characteristics are shown in Table 2. The frequency characteristics outside the measuring frequency of these amplifiers had not yet been standardized at that time, though the frequency nature has now been determined as $-12 \mathrm{~dB} /$ oct. above $90 \mathrm{~Hz}$. Weight of the pickup I was adopted as the minimum value for field use. A sheet of paper was used between the pickup A and the mounting material to evade rattling because the pickup A did not have the legs, although the contact resonance frequency and its peak value might be affected by insertion of this paper.

The vibration tables of electro-dynamic type in the vertical and the horizontal directions were driven by an apparatus connected with a sinusoidal signal oscillator, a calibrated attenuator with $0.1 \mathrm{~dB}$ step and a power amplifier in series. The vibration acceleration level (VAL) given to these pickups for the examination was 


\section{T. MIWA AND Y. YONEKAWA}

selected as $90 \mathrm{~dB}$, in which the reference level of the $\mathrm{dB}$ value $(0 \mathrm{~dB})$ was $10^{-3} \mathrm{~cm} /$ $\mathrm{sec}^{2}$. The vibration frequency was watched by a frequency counter. The output voltage of the vibration pickup mounted on the sample was measured by a vaccumtube-voltmeter and its wave form was scrutinized by an oscilloscope. The motion of the vibration table itself and of the surface of sample was observed by the reference accelerometers as shown in Fig. 1, namely, the one is the vibration accelerometer ( $25 \mathrm{~g}$ in weight and $30 \mathrm{~mm} \times 20 \mathrm{~mm} \phi$ in size) and the other is the smallest accelerometer ( $4 \mathrm{~g}$ in weight and $12 \times 5 \times 5 \mathrm{~mm}^{3}$ in size) which was stuck with a both-surface adhesive cellophane tape or with an adhesive on the sample or was fixed on a small aluminum wedge $(8 \mathrm{~g})$ buried in the soil in the aluminum box.

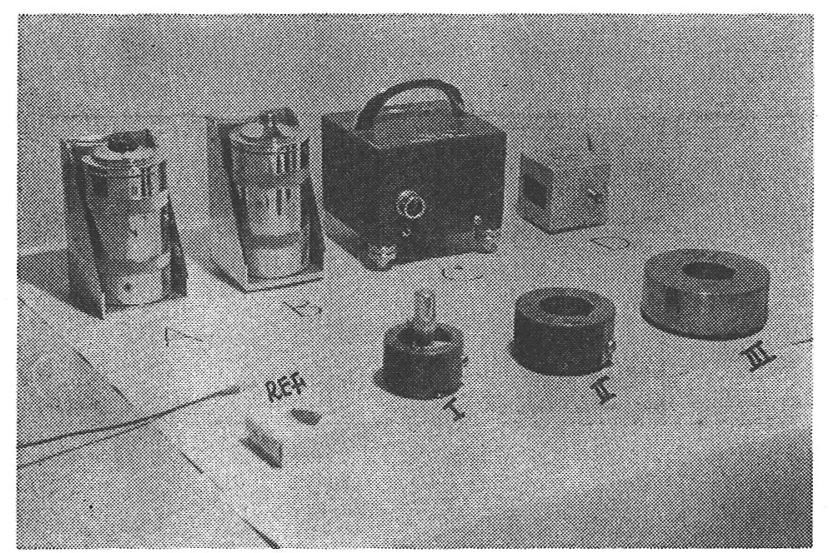

Fig. 1. Photograph of the seven examined vibration pickups. The accelerometer set on the pickup I was used not only as the sensing element of the pickup I, II and III but also as the reference pickup on the vibration table. The accelerometer described as "REF" was employed as the reference on the mounting materials.

At first, the vibration level of the table was adjusted by the attenuator at 90 $\mathrm{dB}$ using reference accelerometer and the attenuator reading was recorded. Then, the output voltage of the vibration pickup mounted on the sample was controlled by the attenuator until $90 \mathrm{~dB}$ and its reading was also recorded. The difference of these two attenuator readings was defined as the frequency response. The frequency was varied between 10 and $300 \mathrm{~Hz}$, because below $10 \mathrm{~Hz}$, there occurs no contact resonance and the range above $300 \mathrm{~Hz}$ was not necessary for measurement of vibration pollution.

\section{Results And Discussions}

The representative results are shown in Figs. $2-10$, in which the ordinate denotes the difference of output voltage $(\mathrm{dB})$ between the reference accelerometer set on the vibration table and the accelerometer mounted on the sample and the 


\section{MOUNTING OF VIBRATION PICKUPS}

abscissa the vibration frequency $(\mathrm{Hz})$. The contact resonance frequency $(\mathrm{Hz})$ observed by the pickup mounted on the sample and its peak value $(\mathrm{dB})$ are tabulated in Tables 3 and 4 for both vibrations. In these tables, lateral lines indicate contact resonance does not occur below $300 \mathrm{~Hz}$. Vibration on the soil was measured by the reference pickup below $250 \mathrm{~Hz}$ for vertical vibration or below $100 \mathrm{~Hz}$ for horizontal vibration because of nonlinearity of the output signal of the pickup. So, the values of the soil in the column of " $\mathrm{REF}$ " are not the contact resonance frequency, but the end frequency and its level difference.

Table 3. Contact resonance frequencies between the vibration pickups and mounting materials $(\mathrm{Hz}$, on the left side in the column) and their peak values ( $\mathrm{dB}$ on the right side) for vertical vibration. Type of the vibration pickups are shown on the line as A, B, C, D, I, II, III and REF, and sorts of the mounting materials on the first column.

\begin{tabular}{|c|c|c|c|c|c|c|c|c|c|c|c|c|c|c|c|c|}
\hline & \multicolumn{2}{|l|}{ A } & \multicolumn{2}{|c|}{ B } & \multicolumn{2}{|l|}{$\mathrm{C}$} & \multicolumn{2}{|l|}{$\mathrm{D}$} & \multicolumn{2}{|l|}{ I } & \multicolumn{2}{|l|}{ II } & \multicolumn{2}{|l|}{ III } & \multicolumn{2}{|c|}{ REF } \\
\hline Aluminum disc & - & - & - & - & - & - & - & - & - & - & - & - & - & - & 一 & - \\
\hline Concrete block & - & - & - & - & - & - & 一 & - & - & 一 & - & - & - & - & - & - \\
\hline Light weight block & - & - & - & - & - & - & 一 & - & - & - & - & - & 270 & 14 & - & - \\
\hline Fire brick & - & - & 290 & 13 & 200 & 5 & - & - & - & - & 一 & - & - & - & - & - \\
\hline Vinyl-tile & - & - & - & - & - & - & - & - & - & - & - & - & - & 一 & - & - \\
\hline Plywood plate & 265 & 18 & 230 & 18 & 190 & 15 & 250 & 26 & - & - & 300 & 25 & 240 & 23 & - & - \\
\hline Lauan plate & 300 & 18 & 230 & 18 & 215 & 8 & 280 & 30 & - & - & - & - & 280 & 22 & - & 一 \\
\hline Wooden-fiber cemented plate & 215 & 21 & 190 & 20 & 170 & 14 & 230 & 31 & - & - & 280 & 30 & 235 & 24 & - & - \\
\hline Cypress rectangular lumber & 245 & 15 & 210 & 16 & 180 & 11 & 270 & 23 & - & - & - & - & 280 & 26 & - & - \\
\hline Soil & 145 & 16 & 138 & 15 & 112 & 17 & 155 & 20 & 213 & 23 & 196 & 22 & 169 & 19 & 250 & 10 \\
\hline Japanese mat & 56 & 16 & 47 & 14 & 41 & 19 & 50 & 17 & 64 & 20 & 50 & 15 & 47 & 17 & 140 & \\
\hline
\end{tabular}

Table 4. Contact resonance frequencies between the vibration pickups and the mounting materials $(\mathrm{Hz}$, on the left side in the column) and their peak values $(\mathrm{dB}$, on the right side) for horizontal vibration.

\begin{tabular}{|c|c|c|c|c|c|c|c|c|c|c|c|c|c|c|c|c|}
\hline \multirow[b]{2}{*}{ Aluminum disc } & \multicolumn{2}{|l|}{ A } & \multicolumn{2}{|l|}{ B } & \multicolumn{2}{|l|}{$\mathrm{C}$} & \multicolumn{2}{|l|}{$\mathrm{D}$} & \multicolumn{2}{|l|}{ I } & \multicolumn{2}{|l|}{ II } & \multicolumn{2}{|l|}{ III } & \multicolumn{2}{|c|}{ REF } \\
\hline & 262 & 10 & - & - & 135 & 19 & - & - & - & - & - & - & - & - & 327 & 17 \\
\hline Concrete block & 260 & 15 & 280 & 8 & 125 & 26 & 240 & 26 & 270 & 13 & 260 & 13 & 260 & 17 & 270 & 9 \\
\hline Light weight block & 115 & 9 & 140 & 21 & 90 & 20 & 190 & 25 & 190 & 21 & 175 & 27 & 160 & 19 & 225 & 14 \\
\hline Fire brick & 80 & 20 & 78 & 21 & 48 & 15 & 100 & 23 & 145 & 22 & 125 & 25 & 103 & 24 & 200 & 25 \\
\hline Vinyl-tile & 一 & - & - & 一 & 120 & 14 & - & - & - & - & - & - & - & - & 329 & 15 \\
\hline Plywood plate & 244 & 11 & 190 & 14 & 80 & 12 & 150 & 20 & 210 & 15 & 165 & 15 & 135 & 15 & 328 & 16 \\
\hline Lauan plate & 255 & 12 & 215 & 15 & 100 & 18 & 160 & 22 & 210 & 19 & 170 & 21 & 170 & 21 & 330 & 11 \\
\hline Wooden-fiber cemented plate & 165 & 12 & 180 & 18 & 70 & 15 & 200 & 17 & 250 & 22 & 205 & 23 & 190 & 14 & 325 & 10 \\
\hline Cypress rectangular lumber & 170 & 21 & 155 & 16 & 90 & 22 & 150 & 26 & 190 & 23 & 160 & 19 & 155 & 17 & 310 & 21 \\
\hline Soil & 70 & 13 & 62 & 12 & 50 & 15 & 60 & 15 & 100 & 20 & 80 & 18 & 70 & 16 & 100 & 8 \\
\hline Japanese mat & 40 & 10 & 38 & 15 & 21 & 11 & 27 & 14 & 26 & 9 & 25 & 7 & 32 & 12 & 130 & 8 \\
\hline
\end{tabular}




\section{T. MIWA AND Y. YONEKAWA}

a) Vertical sinusoidal vibration

The resonance frequency of the vibration table itself in the vertical direction was high above $600 \mathrm{~Hz}$, so it is easy to discriminate the resonance caused by the mounting sample.

On the group of hard samples, the results of the aluminum plate are shown in Figs. 2, $\mathrm{a}$ and $\mathrm{b}$ as the typical example of this group. Their frequency responses are flat below $90 \mathrm{~Hz}$ and different above $90 \mathrm{~Hz}$ depending upon the frequency characteristics of the amplifier of the pickups. On the other samples of this group, the results on the aluminum plate and the concrete block are in good agreement. However, the pickup III set on lightweight block and the pickups of B and C on the fire blick have the resonance below $300 \mathrm{~Hz}$, as indicated in Table 3, while these samples themselves did not have the resonance below $300 \mathrm{~Hz}$. These resonances come from the vibration system consisting of elasticity of the contacted surface of the sample and mass of the pickup, which is called contact resonance. On the vinyl tile, all the pickups show similar response to the aluminum plate. Although

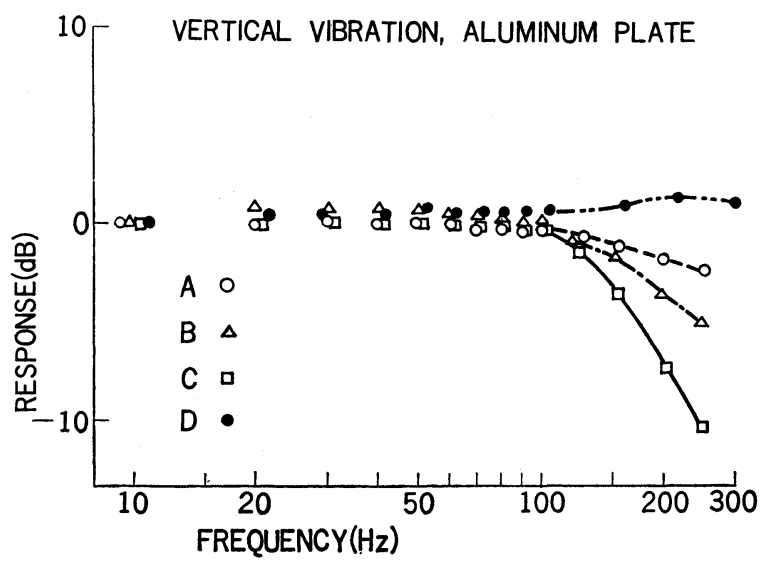

(a)

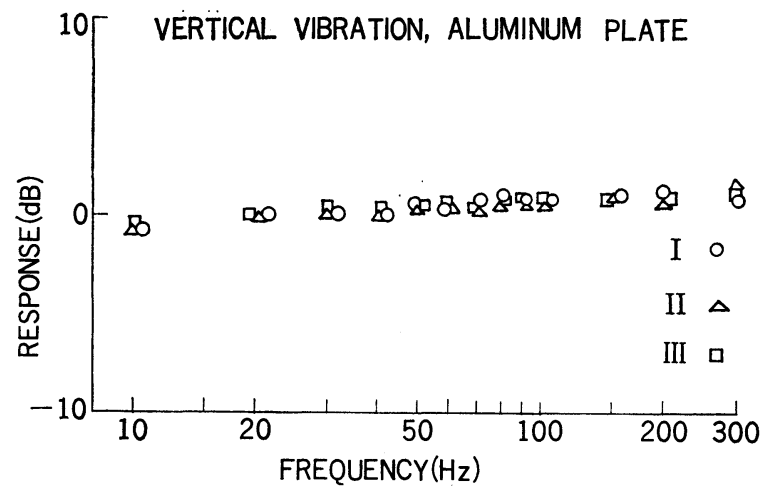

(b)

Figs. 2, $\mathrm{a}$ and $\mathrm{b}$. Frequency responses of 7 vibration pickups on the aluminum plate for vertical vibration. 
MOUNTING OF VIBRATION PICKUPS

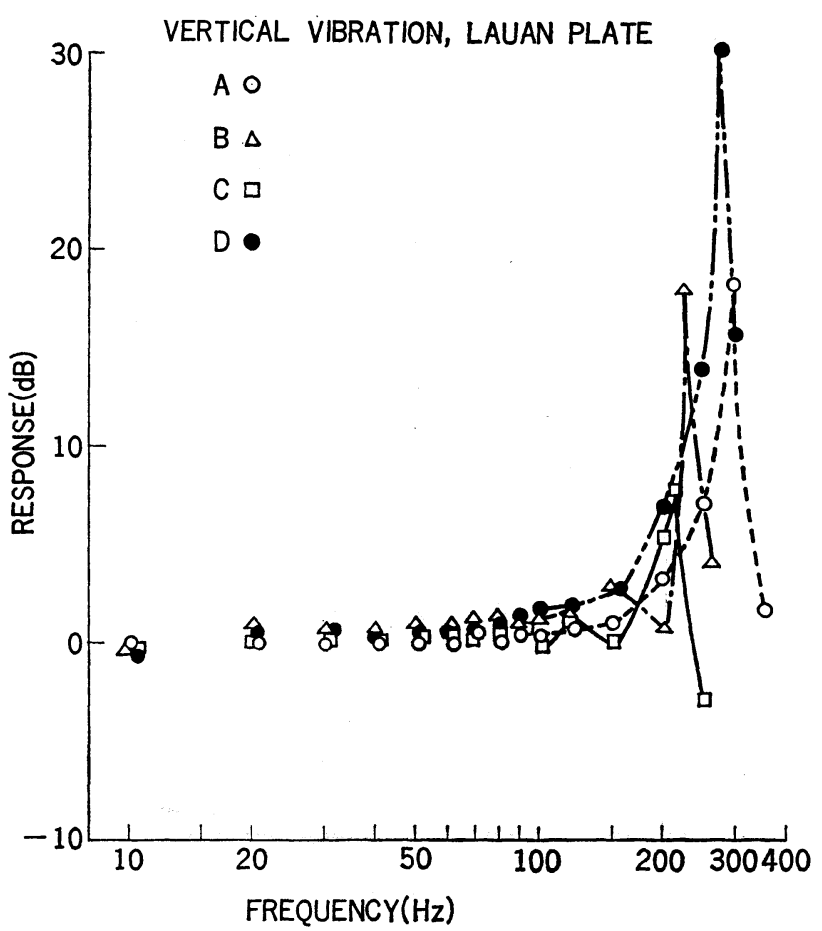

(a)

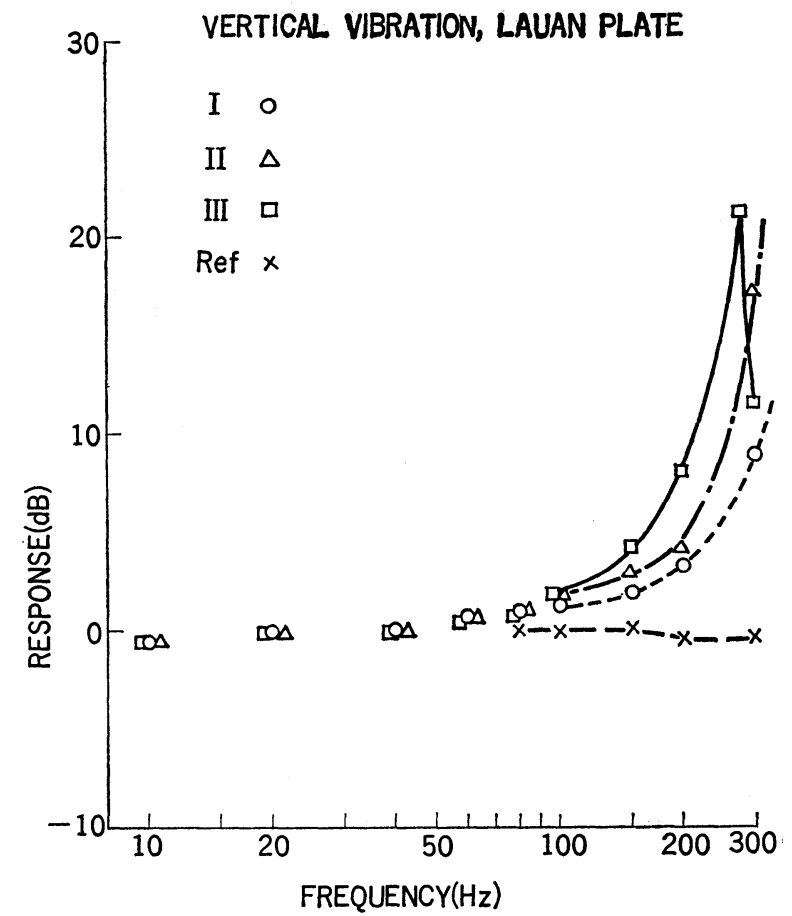

(b)

Figs. 3, a and b. Frequency responses of 7 vibration pickups on the lauan plate for vertical vibration. 


\section{T. MIWA AND Y. YONEKAWA}

elasticity of the vinyl tile affects to some extent the result in higher frequency range, this deviation is less than that of the aluminum plate and in addition it is noticeable that contact resonance does not occur on the vinyl tile due to its viscosity.

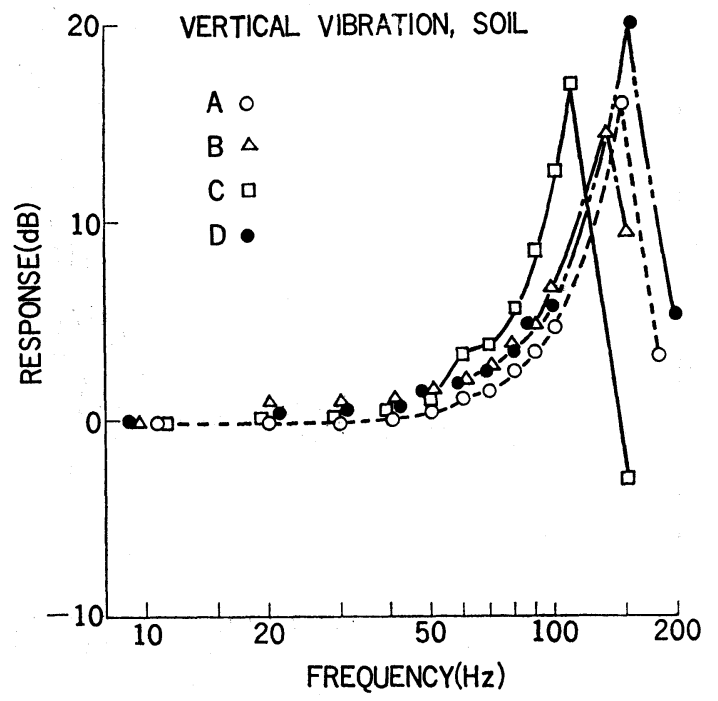

(a)

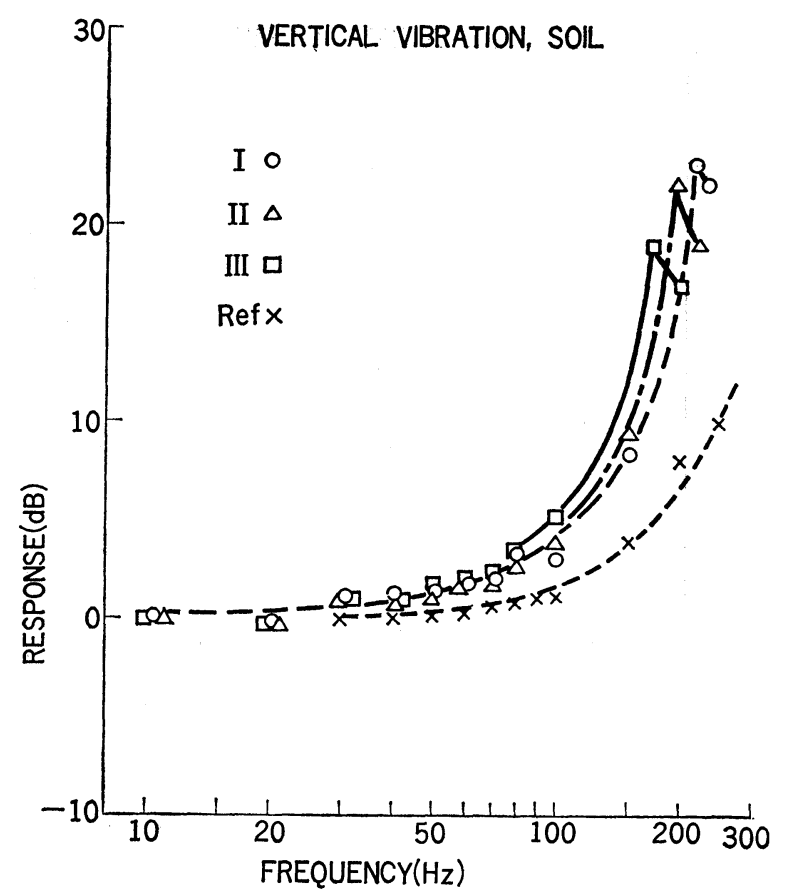

(b)

Figs. 4, a and b. Frequency responses of 7 vibration pickups on the soil for vertical vibration. 


\section{MOUNTING OF VIBRATION PICKUPS}

On the group of wooden materials, tendency of the response of the vibration pickups is almost the same except that the contact resonance frequency is somewhat different depending upon elasticity of the materials. The data observed on the lauan plate are shown as the typical example in Figs. 3, a and b. The lauan plate does not exhibit the peak response by the reference pickup below $300 \mathrm{~Hz}$, but the pickups of A, B, C, D and III denote their peak between 200 and $300 \mathrm{~Hz}$, although the frequency of the amplifiers of $\mathrm{A}, \mathrm{B}$ and $\mathrm{C}$ had been cut above $90 \mathrm{~Hz}$. The other samples of this group have almost similar tendency of the lauan plates as described in Table 3.

On the soil in the soft samples, the results are shown in Figs. 4, a and b. Their resonance peaks gather between 110 and $250 \mathrm{~Hz}$ and the contact resonance frequency between the soil and the pickup nearly decreases with increase of the mass of pickup. The soil itself shows resonance as plotted in Fig. 4, b, $(\times)$, but the deviation between the soil itself and the contact resonacne is considerably large.

The resonance of Japanese mat itself occurs at near $140 \mathrm{~Hz}$. When some pickup is loaded on it, the contact resonance is seen at very low frequency even though its weight is not so large as shown in Figs. 5, a and b. The resonance frequencies of the pickups are concentrated in $50 \mathrm{~Hz}$ within $\pm 10 \mathrm{~Hz}$ and their peak values are similar by about $18 \mathrm{~dB}$ regardless of their weight.

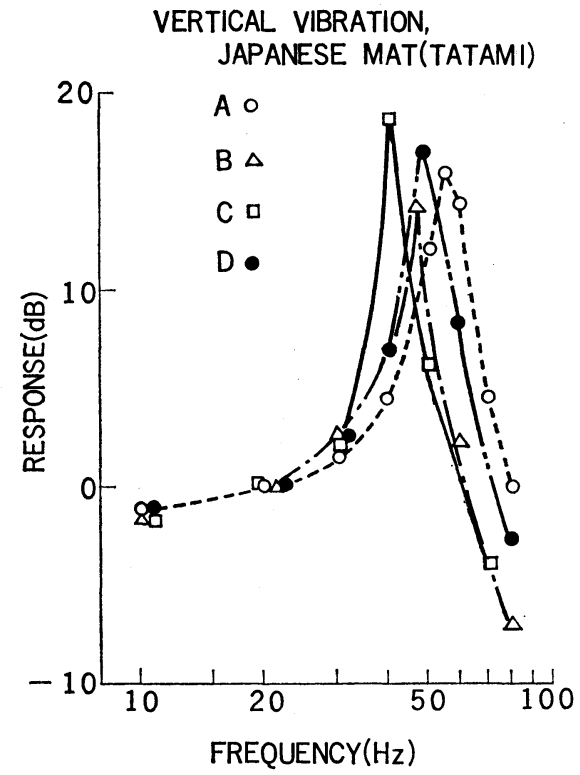

(a)

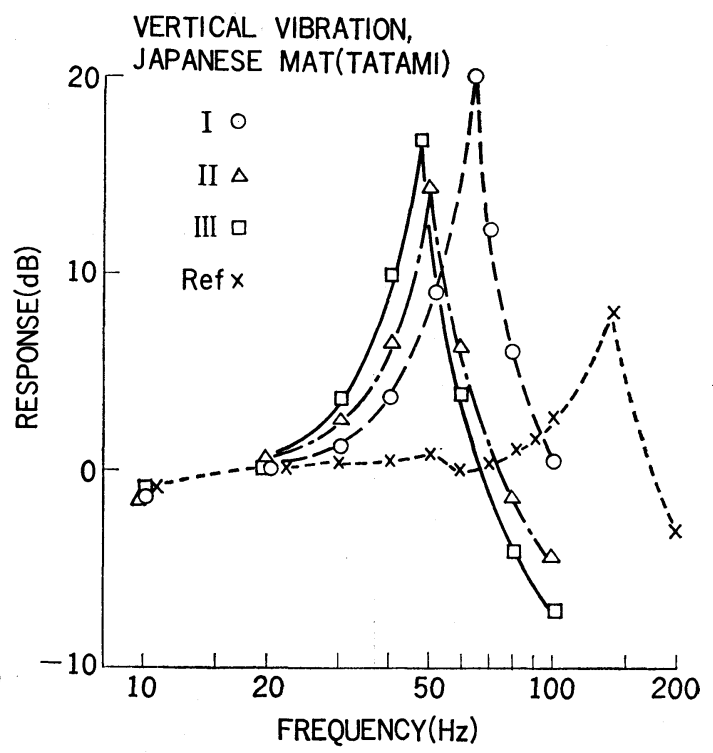

(b)

Figs. 5, a and b. Frequency responses of 7 vibration pickups on the Japanese mat (Tatami) for vertical vibration. 


\section{T. MIWA AND Y. YONEKAWA}

\section{b) Horizontal simusoidal vibration}

Our horizontal vibration table has the resonance frequency at about $330 \mathrm{~Hz}$, so attention has to be paid for data analysis.

On the group of hard samples, the results of aluminum plate are shown in Figs. 6, $a$ and $b$. In these figures, the pickups of B, D, I, II and III show the similar patterns to the reference pickup $(X)$, provided that concave curve of the pickup $\mathrm{B}$ above $100 \mathrm{~Hz}$ comes from the nature of its amplifier. On the other hand, the pickup $\mathrm{C}$ shows the different response, that is, the resonance occurs at $135 \mathrm{~Hz}$, which is lower than the table resonance of $330 \mathrm{~Hz}$. This resonance stems from long legs of this pickup of $25 \mathrm{~mm}$, because this resonance frequency can be shifted

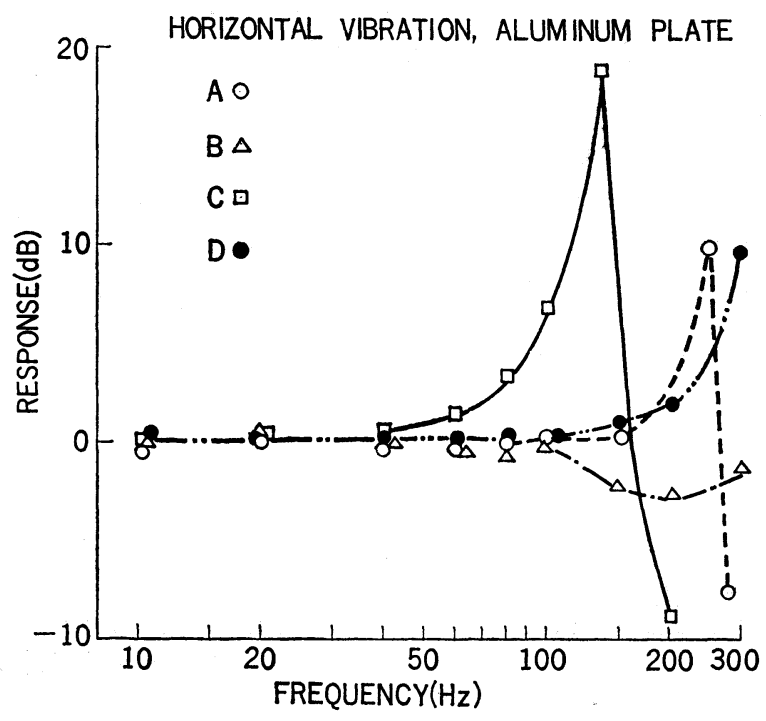

(a)

HORIZONTAL VIBRATION, ALUMINUM PLATE

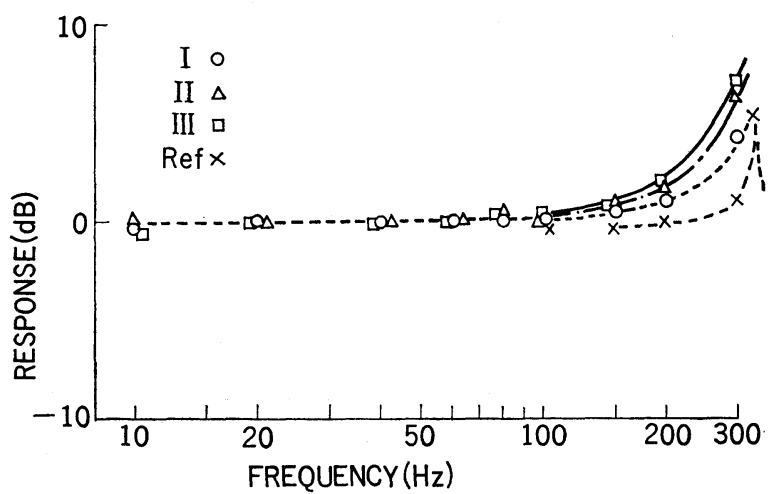

(b)

Figs. 6, a and b. Frequency responses of 7 vibration pickups on the aluminum plate for horizontal vibration. 


\section{MOUNTING OF VIBRATION PICKUPS}

to higher frequency of about $270 \mathrm{~Hz}$ replacing these legs of $5 \mathrm{~mm}$ in length. The contact resonance of this pickup without the above improvement can be seen on the other samples at low frequencies for the horizontal vibration. The pickup A indicates the resonance at about $262 \mathrm{~Hz}$, which comes from its rattling owing to not having their legs and rough bottom surface of the pickup. A sheet of paper was not used in this case.

On the vinyl tile, the pickups except $\mathrm{C}$ show almost similar response curve, barring the resonance occurs rather at lower frequency than that on the aluminum plate due to visco-elasticity of the vinyle tile, although this difference is negligible as described in Table 4.

On the other materials of the hard samples, the resonance frequency of the vibration system composed of the mounting material and the horizontal vibration table is considerably lowered on account of the mass of the material or its fixed condition with bolts on the table. The resonance frequency on the light-weight block observed by the reference pickup takes place at about $225 \mathrm{~Hz}$ as shown in Fig. 7, b and Table 4. The pickups of D, I and II in Figs. 7, a and b show nearly similar response pattern of the reference pickup, while the other pickups indicate rather lower resonance frequency. The lower resonance frequency of the pickups of $\mathrm{B}$ and III comes from their weight.

The resonance of the concrete block itself occurs at about $270 \mathrm{~Hz}$. The pickups except $\mathrm{C}$ may follow the input vibration as shown in Table 4. As the fire blick has light weight but high compliance, its resonance occurs at $200 \mathrm{~Hz}$, which was observed by the reference pickup. All pickups on the fire blick denote lower contact resonance frequencies below $150 \mathrm{~Hz}$ as tabulated in Table 4, especially, the pickups which show the resonance above $100 \mathrm{~Hz}$ are D, I, II and III.

On the group of wooden samples, the resonance frequency between the vibration table and the wooden material bolted on it is the same as that of the table itself checked by the reference pickup as shown in Table 4 . On the other hand, the contact resonance between wooden samples and the pickups, however, is observed below $300 \mathrm{~Hz}$ in all cases. This contact resonance frequency is easily varied within $\pm 20 \mathrm{~Hz}$ as compared with the vertical vibration by the setting position of the sample or use of both-side adhesive cellophane tape or preliminary treatment that the legs of the pickup are rubbed on the material. Besides, contact resonance frequency is lowered in proportion as increase of weight of the pickup, while its peak value is kept at some constant level. The result of lauan plate is shown in Figs. 8, a and $\mathrm{b}$ as the typical example. Lauan plate has so higher stiffness that the contact resonance frequencies fall between 150 and $260 \mathrm{~Hz}$ except the pickup $\mathrm{C}$ and their peak values are about $20 \mathrm{~dB}$ on the fickups D, I, II and III.

Though plywood plate is softer than lauan plate, the result on plywood plate agrees well with that on lauan plate except that the contact resonance on plywood plate occurs at rather lower frequency. 
T. MIWA AND Y. YONEKAWA

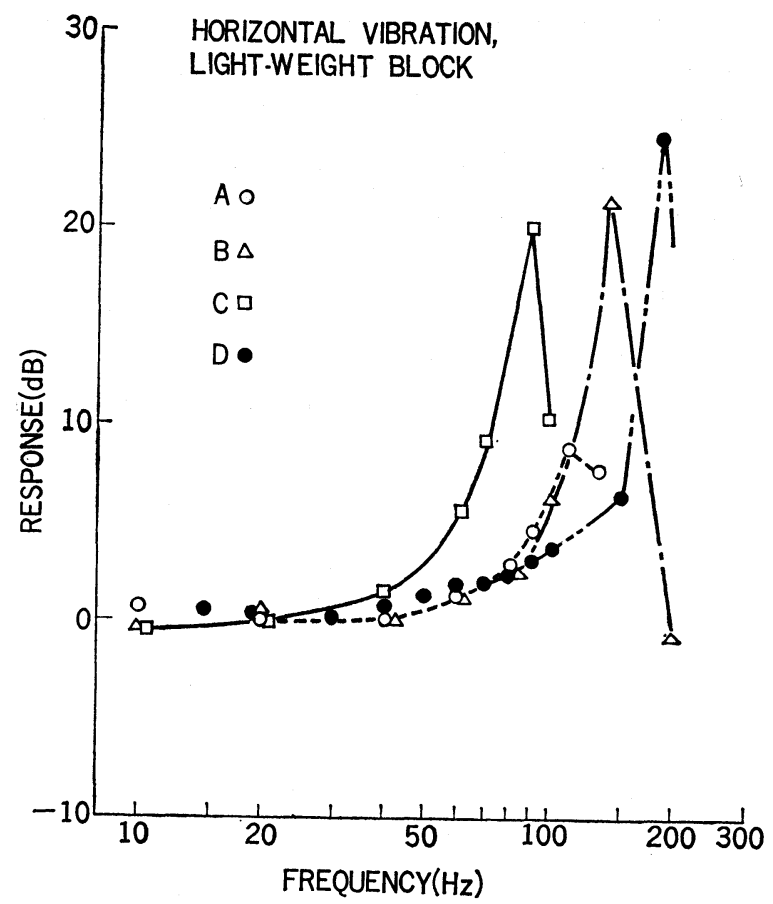

(a)

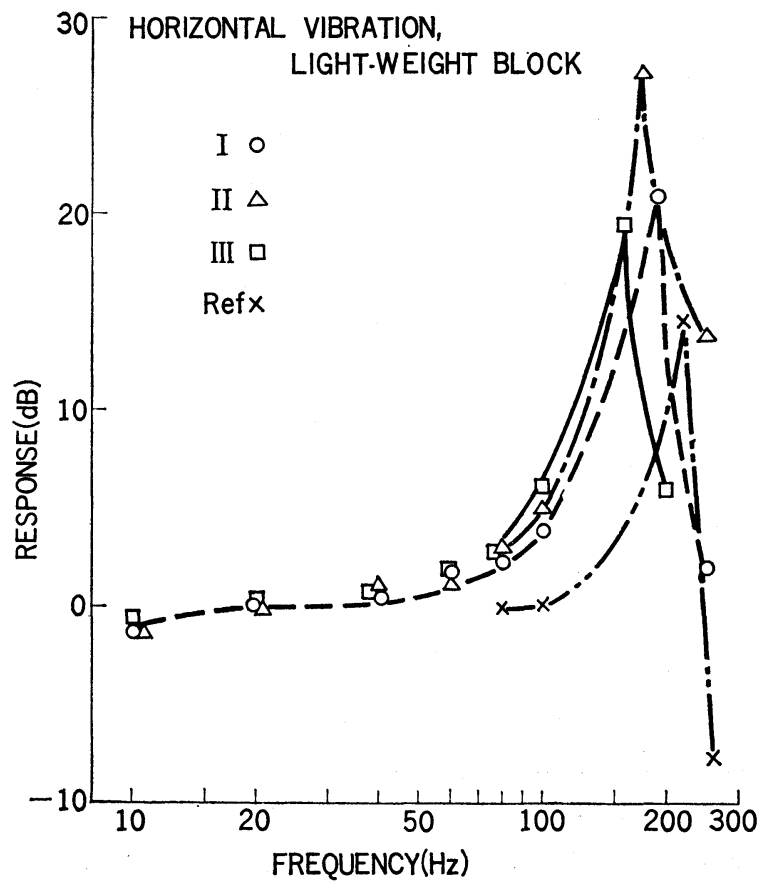

(b)

Figs. 7, a and b. Frequency responses of 7 vibration pickups on the light-weight block for horizontal vibration. 
MOUNTING OF VIBRATION PICKUPS

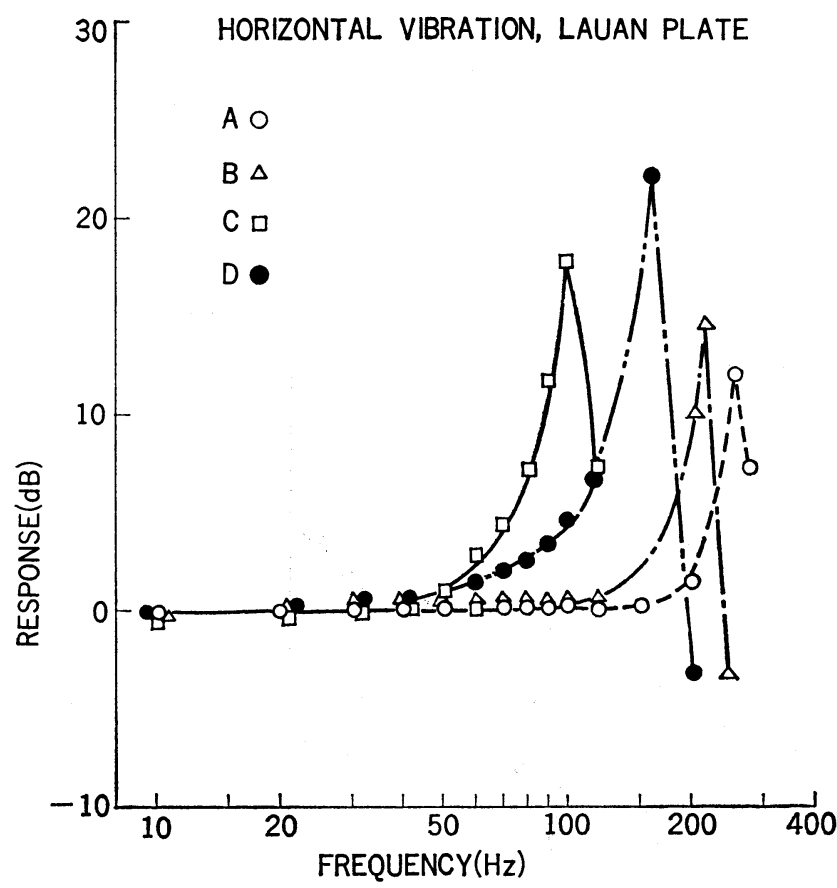

(a)

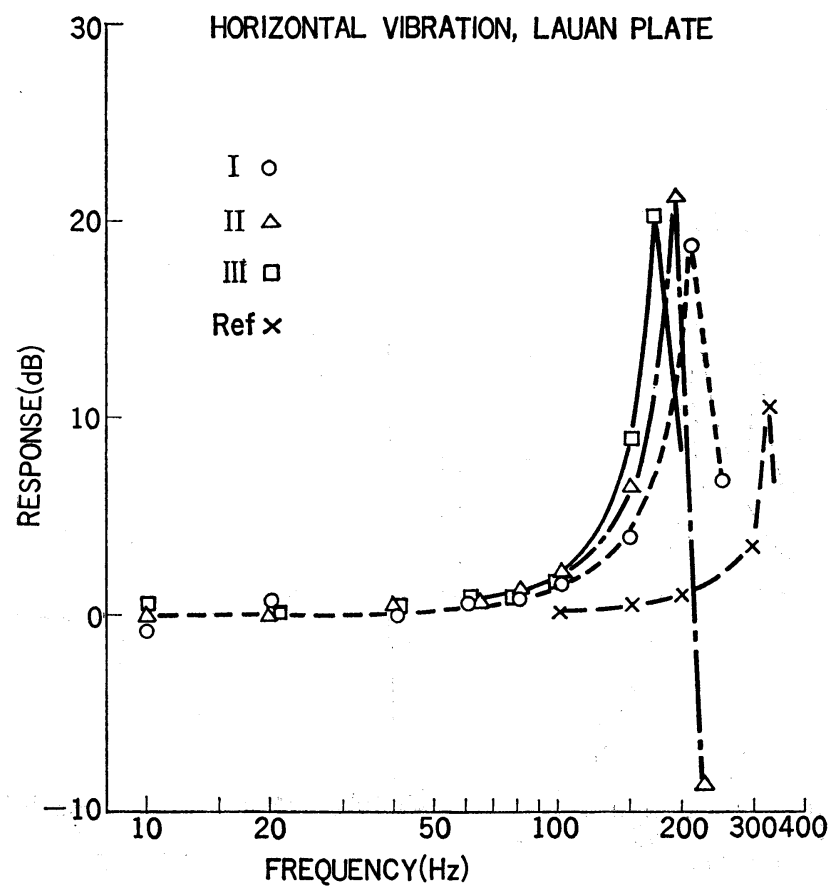

(b)

Figs. 8, a and b. Frequency responses of 7 vibration pickups on the lauan plate for horizontal vibration. 


\section{T. MIWA AND Y. YONEKAWA}

Wooden-fiber cemented plate shows similar response of the other wooden materials as denoted in Table 4. The resonance frequency on cypress square lumber itself is the same as the other plate and the contact resonance of the pickups except $\mathrm{C}$ occurs between 150 and $190 \mathrm{~Hz}$ as shown in Table 4 .

On the group of soft samples, the results of soil are shown in Figs. 9, a and

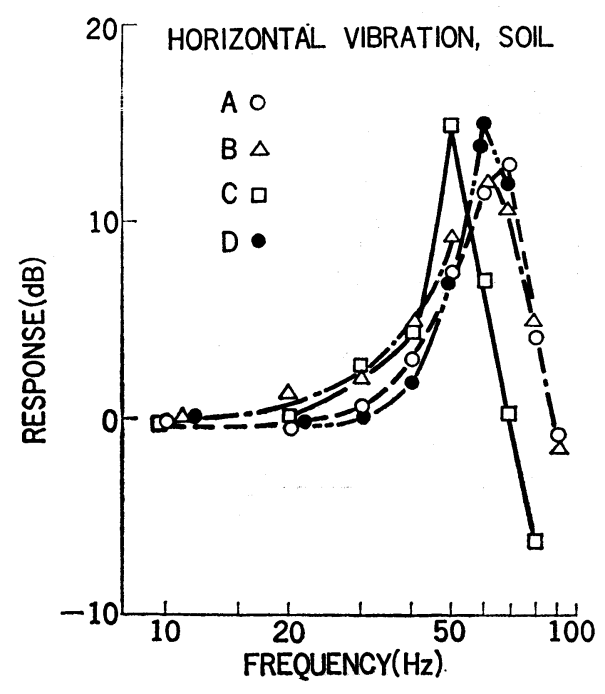

(a)

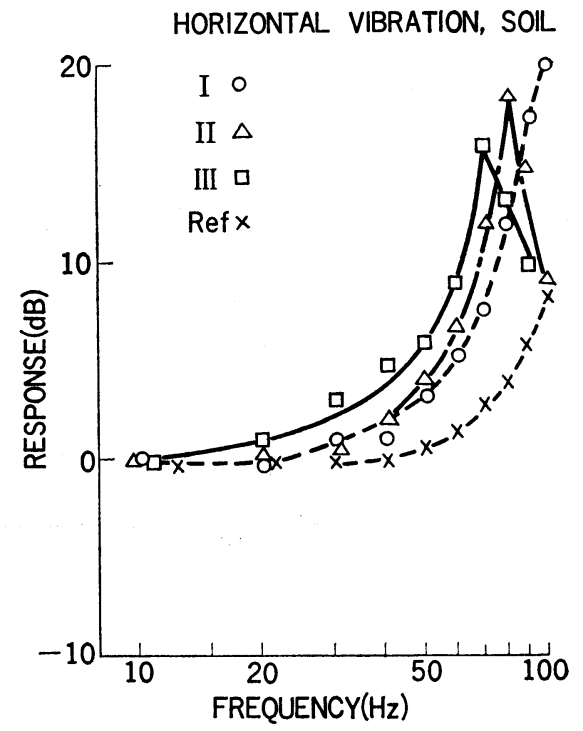

(b)

Figs. 9, a and b. Frequency responses of vibration pickups on the soil for horizontal vibration.

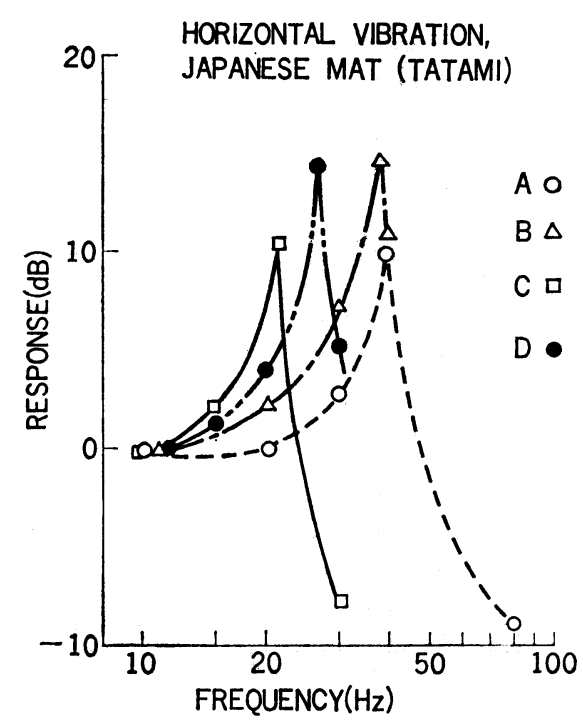

(a)

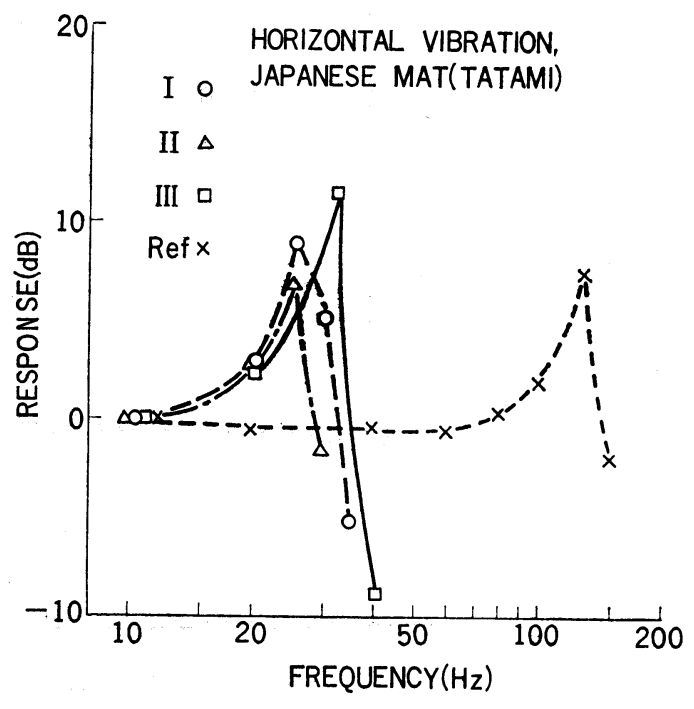

(b)

Figs. 10, a and b. Frequency responses of 7 vibration pickups on the Japanese mat (Tatami) for horizontal vibration. 


\section{MOUNTING OF VIBRATION PICKUPS}

b. The surface of the soil itself has the resonance above $100 \mathrm{~Hz}$. It can be said that weight of the pickup loaded on the soil lowers the contact resonance frequency which gathers in the narrow frequency range betwen 50 and $80 \mathrm{~Hz}$ except the pickup I. The pickup I somewhat elevates this resonance frequency, besides, in case the pickup $I$ is attached with a square aluminum plate of $70 \times 70 \times 3 \mathrm{~mm}^{3}$, the resonance can be shifted to higher frequency owing to widening of the contact surface.

The vibration on the Japanese mat was measured as shown in Figs. 10, a and b. The mat itself shows the resonance at $130 \mathrm{~Hz}$. It is interesting that although the weight, the base area and the legs of the pickups are considerably different with each other, the contact resonance frequencies occur rather in quite narrow frequency range from 20 to $40 \mathrm{~Hz}$ and their peaks have the same height of about $10 \mathrm{~dB}$. Even if the mass of the pickup is lessened, the resonance frequency is not varied so clearly.

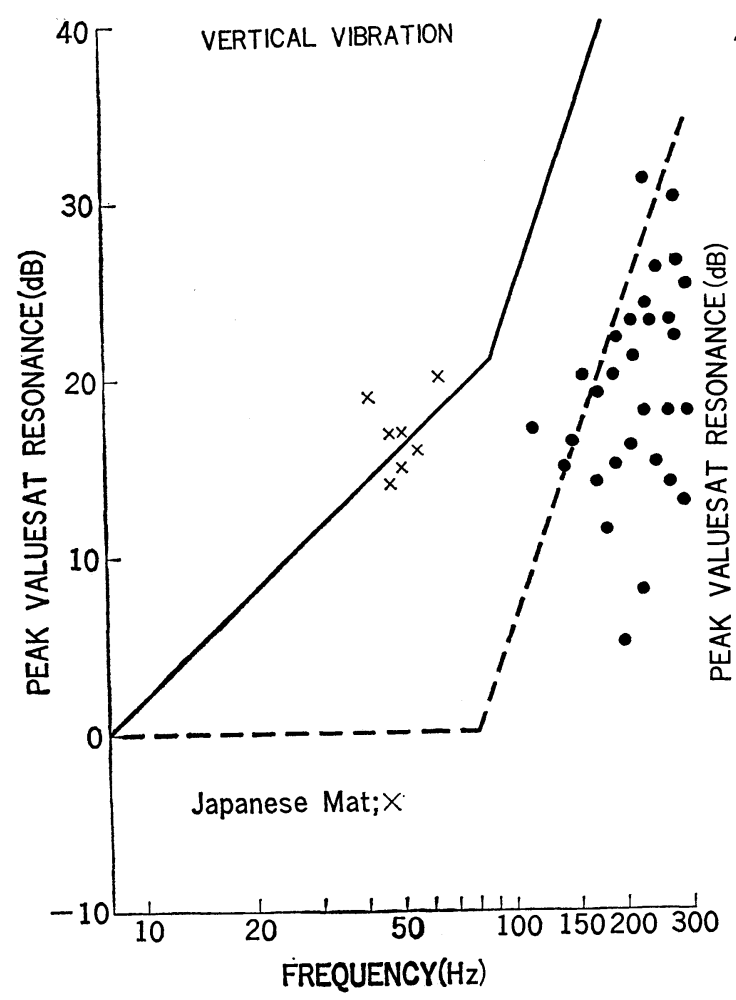

(a)

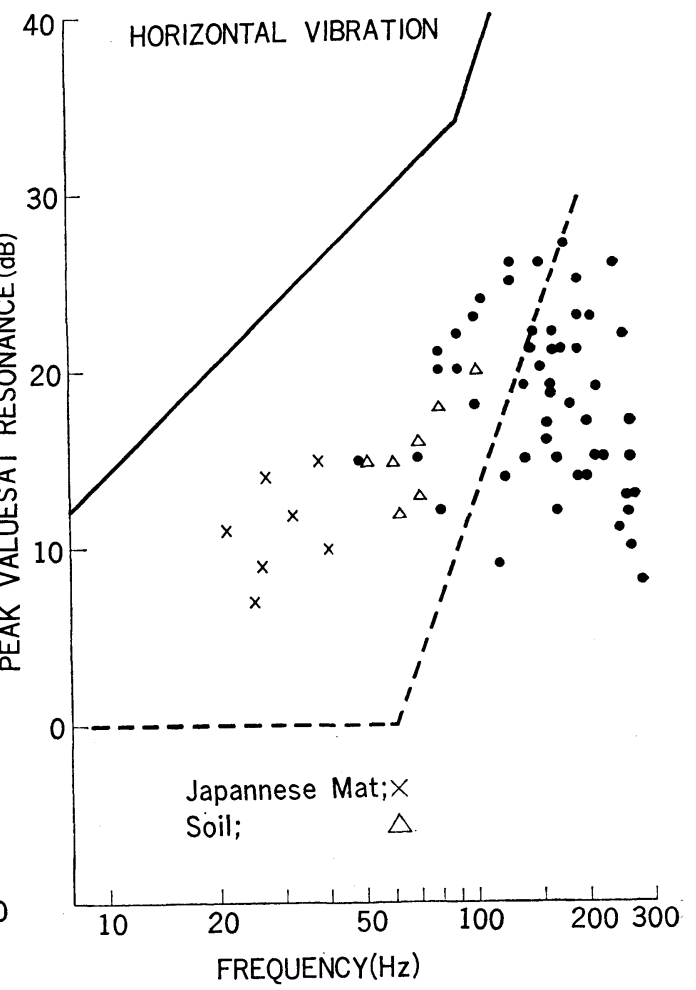

(b)

Figs. 11, a and b. Peak values $(\mathrm{dB})$ at contact resonance frequencies between the vibration pickups and the mounting materials for vertical vibration (a) and for horizontal vibration (b).

On Japanese mat for both vibrations and soil for horizontal vibration, the peak values are discriminated with the signs $(X$ or $\triangle$ respectively) from the other materials $(0)$. The results observed by the reference pickup ("REF") are not included in the figures. 


\section{T. MIWA AND Y. YONEKAWA}

Finally, the peak values at contact resonance frequencies in Tables 3 , and 4 are plotted in Figs. 11, a and b. From these results, the lighter the weight of the pickups, the better result, in which the contact resonance can be elevated to higher frequency range, was obtained for both vibrations. If the vibration acceleration (AL range) is wanted to measure by the pickup of vibration level meter, the cut-off frequencies of the amplifier are better to be selected at 80 or $60 \mathrm{~Hz}$ for both vibrations respectively and above it the cut-off characteristics have to be taken as $-18 \mathrm{~dB} /$ oct. as shown in Figs. 11, a and $\mathrm{b}$ with dotted lines. It is also clarified that the Japanese mat for both vibrations and the soil for horizontal vibration must not be measured by $\mathrm{AL}$ range. Besides, if the VL range of vibration level meter is used, of which the weighting circuit is the same as equal sensation curves in the draft proposed by ISO/TC 108/WG 7 below $90 \mathrm{~Hz}$ and the frequencies above $90 \mathrm{~Hz}$ are cut by more than $-18 \mathrm{~dB} /$ oct., even Japanese mat's measurement seems to be allowed as shown in Fig. 11 with solid lines which are standard lines of $0 \mathrm{~dB}$. On these lines, the frequency ranges between 4 and $8 \mathrm{~Hz}$ for vertical vibration, and 1 and $2 \mathrm{~Hz}$ for horizontal vibration are determined as the acceleration domain and above them as the velocity domain for human vibration sensation.

The contact resonance frequency for the vertical vibration can be easily elevated to the higher frequency above $300 \mathrm{~Hz}$ except the soft samples, while that for horizontal vibration is lowered until near half the value in vertical vibration. The mode of the contact resonance for horizontal vibration seems to stem from the pitching motion of the pickup.

\section{Conclusion}

i) It is desirable to make the contact resonance frequency elevate as high as possible, whatever the mounting materials may be. The pickup I which has weight $(\mathrm{g})$, outside diameter, inside diameter, height and length of legs (mm) of $300,50 \phi$, $35 \phi, 30$ and 4 respectively, and of which the sensing element is supported as low from the bottom as possible, is the best among all tested pickups in order to satisfy the above demand for all mounting samples except Japanese mat.

ii) The vibration measurement in the field of public nuisance shall mainly be made by the VL range of the vibration level meter standardized by the Acoustic Society of Japan. It seems to be required for the vibration level meter below 90 $\mathrm{Hz}$ that the frequency characteristics of the amplifier have to be the same as the equal sensation curves recommended by the ISO/TC 108/WG 7 for both vibrations respectively and above them to be cut as $-18 \mathrm{~dB} /$ oct., although the vibration level meter proposed now has the same weighting characteristics for both vibrations.

iii) The AL range of vibration level meter is desirable to make the frequency characteristics as flat below 80 or $60 \mathrm{~Hz}$ for respective vibrations and above it as $-18 \mathrm{~dB} /$ oct. If vibration on the ground must be measured for $\mathrm{AL}$ range, vertical 


\section{MOUNTING OF VIBRATION PICKUPS}

vibration alone is allowed to measure. At that time, the soil on the spot must be trodden hard enough before setting the vibration pickup. Horizontal vibration on the ground and both vibrations on the Japanese mat must not be measured by $\mathrm{AL}$ range of the vibration level meter. If it is required, vibration measuring method on the soft material obtained by us $^{3)}$ shall be applied.

iv) The calibration of the pickup is possible without bolting it on the vibration table below the vibration level of $90 \mathrm{~dB}\left(0 \mathrm{~dB}=10^{-3} \mathrm{~cm} / \mathrm{sec}^{2}\right)$ in the frequency range between 1 and $300 \mathrm{~Hz}$. It is also known that for the calibration the good results with little deviation is possible to obtain using the aluminum plate or the vinyl tile mounted on the vibration table.

\section{ACKNOWLEDGMENT}

The authors are indebted to Dr. J. Igarashi (Professor of the University of Tokyo), Dr. A. Nakao (Ishikawajima-Harima Heavy Industry Co.) and the other members of the Subcommittee of Vibration Measurement in the Acoustic Society of Japan for valuable advice to pursuit this study.

\section{REFERENCES}

1) Vibration Subcommittee (1970). J. Acoust. Soc. Japan, 26, 10, p. 488 (in Japanese).

2) ISO/TC 108/WG 7 (1970). Draft Recommendation, N-36.

3) Miwa, T. and Yonekawa, Y. (1971). Ind. Health. 9, 81. 